Research Paper

\title{
Impact of Tumor Site on Lymph Node Status and Survival in Colon Cancer
}

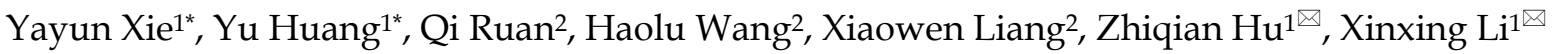 \\ 1. Department of General Surgery, Changzheng Hospital, the Second Military Medical University, 415 S. Fengyang Road, Shanghai. 200003, China \\ 2. The University of Queensland Diamantina Institute, University of Queensland, Translational Research Institute, Brisbane, QLD 4102, Australia \\ *Yayun Xie and Yu Huang have contributed equally to this work. \\ $\square$ Corresponding authors: huzhiq163@163.com or xingxin123456@sina.com
}

(c) Ivyspring International Publisher. This is an open access article distributed under the terms of the Creative Commons Attribution (CC BY-NC) license (https:// creativecommons.org/licenses/by-nc/4.0/). See http://ivyspring.com/terms for full terms and conditions.

Received: 2018.12.05; Accepted: 2019.04.12; Published: 2019.05.26

\begin{abstract}
Objective Our objective was to explore the impact of tumor sites on lymph node (LN) status and prognosis in non-distant metastasis colon cancer after radical operation.

Methods Surveillance, epidemiology, and end results (SEER) database was used to identify 124, 836 early-stage colon cancer patients between 1988 and 2010, treated with radical surgery with a known tumor site. Seven tumor sites were defined as ascending, hepatic, cecum, transverse, descending, splenic, and sigmoid colons by the anatomical location. The associations of tumor site and LN status, including adequate $(\geq 12) \mathrm{LN}$ harvest and $\mathrm{LN}$ positivity, were examined with logistic regression, adjusting for multiple covariates. Relative survival was compared in a flexible parametric model.

Results The quartile number of $L N$ examined gradually decreased from ascending to sigmoid colon cancer ( $\mathrm{P}<0.001$ for all patients, and T2, T3 and T4 stages). More numbers of LN examined and a higher proportion of $L N$ positivity were retrieved in left-half colon cancer than in right-half colon cancer. Cumulative incidence of death (CID) was higher in patients with less LN examined except for the group of cecum colon cancer, but there was no significant difference between all groups (5-year CID: $18.99 \% \sim 21.98 \%$ for $L N$ count $\geq 12$ and $23.01 \% \sim 26.89 \%$ for $L N$ count $<12$ ).

Conclusions $\mathrm{LN}$ examined and $\mathrm{LN}$ positivity in colon cancer were important prognostic factors. There was no significant CDI difference between groups with different tumor sites. Current guidelines for extent of resection should take this into consideration so that and unnecessary treatment may be avoided.
\end{abstract}

Key words: colon cancer, tumors site, lymph node, survival

\section{Introduction}

Colorectal cancer $(\mathrm{CRC})$ is one of the most common gastrointestinal malignancies worldwide. It has been reported that there were about $1,360,000$ new CRC cancer cases and 694, 000 deaths in 2012 all over the world [1]. In China, the incidence of CRC is among the top 5 of all malignant tumors, of which 376,000 were diagnosed as new cases and 191, 000 people died of this disease from the latest statistical data of cancer[2]. Radical resection for colon cancer is based on different tumor sites, such as left side colon resection for descending colon cancer and right side colon resection for ileocecal carcinoma[3]. There are embryological, anatomical, histological, genetic, and immunological differences between right side colon and left side colon. Patients with right-sided colon cancer are often older and more likely to be female, developing a more advanced clinical stage and poorly differentiated tumors[4-5]. A large number of clinical and laboratory studies have shown that there are differences in signaling pathways between the proximal and distal colorectal cancer[6-10]. The right side colon cancer is more prone to be with expansive 
growth, highly microsatellite instability (MSI), CpG methylation and BRAF mutation while the left side colon cancer tends to be invasive growth, chromosomal instability and aneuploidy[7-8]. Moreover, the distal colon cancer is associated with inactivation of tumor suppressor gene (such as APC, P53 and SMAD4), KRAS mutation, and CpG island methylation phenotype compared to the proximal colon cancer that is characterised as oncogene activation, BRAF mutation, methylation inactivation of MLH1, and positive expression of MSI[8-11]. Therefore, the variations in the gene molecular pathways lead to clinically symptomatic and prognostic differences between the proximal and distal colorectal cancer[5, 7-8].

However, the prognostic relevance of laterality in colon cancer still remains controversial[5, 12]. Many studies have reported the poorer oncologic outcomes in patients with right side colon cancer compared to patients with left side colon cancer[12-14]. Karim et al. [5] recently reported that there were no differences in long-term survival for right-sided and left-sided colon cancer. These studies did not show a clear association between the tumor sites and lymph node (LN) status or survival. In this study, we defined ascending, hepatic, cecum, transverse, descending, splenic, and sigmoid colons as seven different tumor sites of colon cancer, and then the Surveillance, Epidemiology, and End Results Program (SEER) database was used to investigate the impact of tumors sites on LN status and prognosis in non-distant metastasis colon cancer after radical operation.

\section{Methods}

\section{Patients and Study Design}

The SEER database and SEER-stat software (SEER*Stat 8.3.2) were used to identify patients whose pathological diagnosis as colon cancer between 1998 and 2010. Only patients who underwent radical surgical treatment with a specific site of diagnosis $\geq 18$ years were included. Histological type was limited to adenocarcinoma (8140/3), mucinous adenocarcinoma $(8480 / 3,8481 / 3)$ and signet ring cell carcinoma (8490/3). Primary sites of colon (C18.0, C18.2-C18.7) were used. Seven different tumor parts of colon cancer were defined as ascending, hepatic, cecum, transverse, descending, splenic, and sigmoid colons following the anatomical sites. Briefly, besides tumor site, main information collected included demographics (year of diagnosis, sex, race, age), tumor characteristics (grade, histological type, extension of primary tumor invasion, number of $\mathrm{LN}$ examined and positive $\mathrm{LN}$, and adjuvant radiotherapy). All patients included had standard colon cancer operations, based on the SEER coded description of surgical procedures. Local excision and local destruction procedures were excluded because of the lack of expectation of obtaining LN. Patients with unknown tumor site, $\mathrm{T}$ stage, or the number of positive LNs were excluded. To eliminate the effect of preoperative radiation on LN harvest and positivity, patients who received radiotherapy prior to surgery were excluded.

\section{Statistical Analysis}

Baseline characteristics were compared using the $X^{2}$ test for nominal variables. Trends in the median number of LN examined by site were estimated using the quantile regression model[15]. Proportions of patients with adequate $(\geq 12)$ LN harvest or with node-positive disease were compared using multivariable Poisson models with robust standard errors. Cox regression models were built for analysis of risk factors for survival outcomes. Relative survival, defined as observed survival/expected survival and calculated using the Pohar Perme method, was the primary endpoint to estimate excess mortality in colon cancer patients compared with the general population without relying on accurate classification of causes of death, described by Khan et al. and Permeet al.[16-17]. The expected mortality was derived from the US National Center for Health Statistics life tables, including these clinical parameters, such as year of diagnosis, sex, race, age, and so on.

The cumulative incidence of death (CID) from colon cancer and from other competing causes was calculated using Cronin and Feuer's method, described by Cronin et al.[18], which provided more realistic estimates of cancer-related mortality than net estimates (such as those obtained from Kaplan-Meier analysis). The interaction between site and adequate nodal harvest was first tested in a general model, and then coefficients were estimated for each site group. Statistical analyses were performed using the statistical software package SPSS 19.0 and SAS 9.0. All $\mathrm{P}$ values were two-sided. $\mathrm{P}<0.01$ was considered statistically significant.

\section{Results}

Table 1 listed the characteristics of the patient population. We identified 124, 836 patients who met the eligibility criteria of this study. Most patients were diagnosed as sigmoid colon cancer $(29.42 \%, \mathrm{n}=36$, $730)$, cecum colon cancer $(24.73 \%, n=30,869)$ or ascending colon cancer $(19.91 \%, \mathrm{n}=24,849)$. Only $4.07 \%$ of patients had splenic colon cancer, occupying the least proportion. The proportion of different parts 
of the tumor at intervals of every four years from 1998 to 2010 was gradually descending as the following order: sigmoid, cecum, ascending, transverse, descending, hepatic and splenic colon except for the years between 2000 and 2003, in which the incidence rates of descending colon cancer and hepatic colon cancer were similar. Sigmoid colon and cecum tumors were the most common ones in male patients, while in female patients, the most prevalent one is sigmoid colon tumors. In addition, splenic flexure carcinoma was the rarest in both male and female patients. Among all seven sites of the tumor, cecum colon cancer, which is most likely to appear in elderly patients ( $\geq 71$ years old) $(28.21 \%)$, was a special type of colon cancer, that it harbored more mucinous adenocarcinoma $(32.44 \%)$ and signet ring cell carcinoma $(34.02 \%)$, more LNs metastasis (N2: $29.51 \%)$, more grade III/ IV (30.34\%) and more adequate LNs dissection (27.03\%), and patients with this type of colon cancer suffered the highest cancer-related mortality than other six groups. On the contrary, sigmoid colon cancer usually occurred among younger (40 70 years old) patients. Majority of the cases were grade I/ II $(32.13 \%)$, adenocarcinoma $(31.71 \%)$ and less LNs metastasis (N0-N1: 60.41\%), but with more depth of tumor invasion (T3-T4: 28.04\%) and inadequate LN dissection (36.55\%). However, most sigmoid colon cancer patients received adjuvant radiation $(54.57 \%)$ as the treatment.

Patients were divided into seven groups according to their tumor locations as ascending, hepatic, cecum, transverse, descending, splenic, and sigmoid colons of number 1-7 (Fig 1A). Patients in all stages had the median number of LNs examined $(\mathrm{n}=13)$, and the median number of LNs examined was 12, 13, 14, and 12 for stages T1, T2, T3 and T4, respectively (Table $2 \mathrm{~A}$ and $2 \mathrm{~B}$ ). The median number of LNs examined decreased from site 1 to 7 for all stages and stage T2-T4 (Table 2A and 2B, P <0.0001). With adequate LNs harvest, the proportion of $\mathrm{LN}$ positivity decreased for all stages from site 1 to 7 (Fig 1B, P<0.0001, Supplementary Table 1, available online). Compared with the group of site 7 , the odds risk of adequate LNs harvest $(\geq 12)$ was 2.292, 1.999, $1.884,1.333,1.200,1.156$ and for groups with site 1 to 6 respectively (Supplementary Table $1, \mathrm{P}<0.001$ ). In a multivariable model after adjusting for year of diagnosis, sex, race, age, grade, histological type, $\mathrm{T}$ stage, and adjunctive therapy, the relative risk (RR) of LN positive was 1.355 (95\% CI, 1.337-1.373) for group of site 1, 1.301 (95\% CI, 1.277-1.326) for site 2, 1.285 (95\% CI, 1.269-1.302) for site 3, 1.129 (95\% CI, 1.109-1.150) for site 4, 1.079 (95\% CI, 1.055-1.104) for site 5, and 1.058 (95\% CI, 1.030-1.087) for site 6 (Table $3, \mathrm{P}<0.001)$, compared with the reference group of site 7.

Then, we analyzed the proportion of patients with at least one positive LN within all stages and classified them by number of LNs examined ( $<12$ and $\geq 12$ ). As shown in Figure $2 \mathrm{~A}-2 \mathrm{C}$, the proportion of positive LNs from site 1,2 , or 4 was less than that from site 3, 5, 6 or 7. Furthermore, 1, 2, and 4 were thought to be right hemi colon cancer, while 5, 6 and 7 to be left hemi colon cancer. Due to the special clinical characteristics of cecum carcinoma (site 3), it is not included in any group. Our results showed that right side colon had a reduced risk of LN positivity at diagnosis regardless of adequate LNs harvest or not (Figure 2D). In an adjusted multivariable model mentioned before that is limited to patients with adequate staging, compared with the reference group of site 7, the RR of node-positive disease was 0.856 (95\% CI, 0.836-0.877) for site 1, $0.858(95 \% \mathrm{CI}$, $0.827-0.891$ ) for site $2,0.933$ (95\% CI, 0.913-0.954) for site 3, 0.854 (95\% CI, 0.827-0.882) for site 4, 0.954 (95\% CI, 0.922-0.988) for site 5, and $0.956(95 \% \mathrm{CI}$, 0.917-0.997) for site 6 respectively (Table 4, $\mathrm{P}<0.001$ ).

Furthermore, we assessed the impact of tumor sites on the survival of colon cancer patients. According to univariate analysis, tumor site was associated with the survival outcome of patients with colon cancer (Supplementary Table 2, P<0.001, available online). In multivariate Cox analysis, tumor site was an independent prognostic factor (Table 3, $\mathrm{P}<0.001)$ after adjusting for multiple covariates. As shown in Supplementary Table 3 (available online), the relative survival was significantly better for patients who had $\geq 12$ LNs harvested $(79.83 \%$ at 5 years; $95 \%$ CI: $79.5 \%-80.12 \%$ ) compared with those who did not $(75.07 \%$ at 5 years; $95 \%$ CI: $74.69 \%-75.45 \%, \mathrm{P}<0.001)$. Cumulative incidence of death (CID) was higher in patients with inadequate LNs harvest except for the cecum colon cancer, but was no significant CDI difference between groups with different tumor sites (Fig 3 and 4, 5-year CID: LNs count $\geq 12: 18.99 \% \sim 22.41 \%$; LNs count $<12$ : $23.01 \% \sim 29.32 \%)$. In the adapted multivariable models adjusting for year of diagnosis, sex, race, age, grade, histological type, $\mathrm{T}$ stage, and adjunctive therapy, the survival benefit of adequate LNs harvest was independent of age (P for interaction, 0.473). Finally, in models fitted separately for each site category, the hazard ratio (HR) for $12 \mathrm{LN}$ examined was 0.681 (95\% CI 0.644-0.719) in patients sited 1, 0.695 (95\% CI, $0.631-0.764)$ in those aged sited 2, $0.684(95 \% \mathrm{CI}$, 0.654-0.715) in those sited 3, 0.793 (95 CI, 0.737-0.854) in those sited $4,0.725$ (95\% CI, 0.663-0.792) in those sited 5, 0.720 (95\% CI, 0.648-0.801) in those sited 6 and $0.760(95 \% \mathrm{CI}, 0.729-0.792)$ in those sited 7 (Supplementary Table 4, $\mathrm{P}<0.0001$, available online). 
Table 1. Patient characteristics of groups with different tumor sites*

\begin{tabular}{|c|c|c|c|c|c|c|c|c|c|}
\hline \multirow[t]{2}{*}{ Parameter } & \multirow[t]{2}{*}{ Characteristic } & \multicolumn{7}{|c|}{ Primary site (colon cancer) } & \multirow[t]{2}{*}{$\mathbf{P}$} \\
\hline & & Ascending & Hepatic & Cecum & Transverse & Descending & Splenic & Sigmoid & \\
\hline \multirow{7}{*}{$\begin{array}{l}\text { Year of } \\
\text { diagnosis }\end{array}$} & & & & & & & & & 0.00 \\
\hline & 1988 1991 & 1165(15.35) & $407(5.36)$ & 1928(25.41) & $710(9.36)$ & $563(7.42)$ & $329(4.34)$ & 2487(32.77) & \\
\hline & 1992 1995 & 1899(16.23) & $711(6.08)$ & $3016(25.78)$ & $1104(9.44)$ & $761(6.51)$ & $484(4.14)$ & $3722(31.82)$ & \\
\hline & 1996 1999 & 2234(17.59) & $774(6.10)$ & $3210(25.28)$ & $1186(9.34)$ & $836(6.58)$ & $581(4.58)$ & $3876(30.53)$ & \\
\hline & $2000 \sim 2003$ & $6773(20.27)$ & $2060(6.16)$ & $8285(24.79)$ & $3279(9.81)$ & $2042(6.11)$ & $1387(4.15)$ & $9591(28.70)$ & \\
\hline & 2004 2007 & 7184(21.17) & $1869(5.51)$ & $8150(24.02)$ & $3240(9.55)$ & $2168(6.39)$ & $1375(4.05)$ & 9948(29.32) & \\
\hline & 2008 2010 & $5594(21.94)$ & $1421(5.57)$ & $6280(24.63)$ & 2582(10.12) & $1588(6.23)$ & $931(3.65)$ & $7106(28.86)$ & \\
\hline \multirow[t]{3}{*}{ Sex } & & & & & & & & & 0.00 \\
\hline & Male & 14050(20.94) & $3817(5.69)$ & 17955(26.76) & 6691(9.97) & $3916(5.84)$ & $2449(3.56)$ & $18206(27.14)$ & \\
\hline & Female & 10799(18.70) & $3425(5.93)$ & $12914(22.36)$ & $5410(9.37)$ & $4042(7.00)$ & $2638(4.57)$ & $18524(32.08)$ & \\
\hline \multirow[t]{4}{*}{ Race } & & & & & & & & & 0.00 \\
\hline & White & $20170(20.28)$ & $5823(5.86)$ & $25433(25.57)$ & $9612(9.67$ & $5847(5.88)$ & $3830(3.85)$ & 28731(28.89) & \\
\hline & Black & 2843(19.79) & $770(5.26)$ & $3586(24.96)$ & $1471(10.24)$ & 1202(8.37) & $813(5.66)$ & $3608(25.12)$ & \\
\hline & Others & $1836(16.65)$ & $649(5.89)$ & 1850(16.78) & $1018(9.23)$ & $909(8.24)$ & $444(4.03)$ & $4319(39.17)$ & \\
\hline \multicolumn{10}{|l|}{ Age } \\
\hline & $18 \sim 40$ & $550(15.58)$ & $210(5.59)$ & $656(18.58)$ & $384(10.88)$ & $371(10.51)$ & $195(5.52)$ & 1164(32.97) & \\
\hline & $41 \sim 70$ & 10030(17.27) & $3064(5.27)$ & $12380(21.31)$ & $5399(9.29)$ & $4222(7.27)$ & $2608(4.49)$ & 20383(35.09) & \\
\hline & $71+\sim$ & $14269(22.57)$ & $3968(6.28)$ & $17833(28.21)$ & 6318(9.99) & $3365(5.32)$ & $2284(3.61)$ & $15183(24.02)$ & \\
\hline \multirow[t]{4}{*}{ Grade } & & & & & & & & & 0.00 \\
\hline & I/ II & 18234(18.84) & $5277(5.45)$ & 22435(23.19) & $9125(9.43)$ & $6542(6.76)$ & 4055(4.19) & $31091(32.13)$ & \\
\hline & III/ IV & 5964(24.09) & 1771(7.15) & 7511(30.34) & $2638(10.65)$ & $1209(4.88)$ & $906(3.66)$ & $4760(19.23)$ & \\
\hline & Unknown & 651(19.62) & 194(7.78) & $923(27.82)$ & $338(10.19)$ & $207(6.24)$ & $126(3.80)$ & $879(26.49)$ & \\
\hline \multirow[t]{4}{*}{ His- } & & & & & & & & & 0.00 \\
\hline & AC & 20260(18.99) & $5934(5.56)$ & 24952(23.39) & $10205(9.57)$ & $7048(6.61)$ & $4437(4.16)$ & $33826(31.71)$ & \\
\hline & $\mathbf{M u}$ & $4251(25.21)$ & $1206(7.15)$ & $5471(32.44)$ & $1749(10.37)$ & $848(5.03)$ & $603(3.58)$ & $2735(16.22)$ & \\
\hline & SRC & $338(25.78)$ & 102(7.78) & $446(34.02)$ & 147(11.21) & $62(4.73)$ & $47(3.59)$ & $169(12.89)$ & \\
\hline \multirow[t]{3}{*}{ T stage } & & & & & & & & & 0.00 \\
\hline & T1/ T2 & $5091(20.68)$ & 1197(4.86) & $6115(24.84)$ & $2027(8.23)$ & $1252(5.09)$ & $668(2.71)$ & $8265(33.58)$ & \\
\hline & T3/ T4 & 19758(19.71) & $6045(6.03)$ & $24754(24.70)$ & 10074(10.05) & $6706(6.69)$ & $4419(4.41)$ & $28465(28.40)$ & \\
\hline \multirow[t]{4}{*}{ N stage } & & & & & & & & & 0.00 \\
\hline & No & 15598(20.83) & $4584(6.12)$ & 18053(24.11) & 7587(10.13) & $4739(6.33)$ & $2950(3.94)$ & $21367(28.54)$ & \\
\hline & N1 & $5889(18.31)$ & $1802(5.60)$ & $7563(23.52)$ & $3076(9.56)$ & $2136(6.64)$ & $1446(4.50)$ & $10248(31.87)$ & \\
\hline & N2 & 3362(18.89) & $856(4.81)$ & $5253(29.51)$ & $1438(8.08)$ & $1083(6.08)$ & $691(3.88)$ & $5115(28.74)$ & \\
\hline \multirow[t]{3}{*}{ LNs } & & & & & & & & & 0.00 \\
\hline & $<12$ & $7618(15.06)$ & $2436(4.82)$ & $10796(21.34)$ & $5226(10.33)$ & $3644(7.20)$ & $2376(4.70)$ & $18486(36.55)$ & \\
\hline & $\geq 12$ & $17231(23.21)$ & $4806(6.47)$ & $20073(27.03)$ & $6875(9.26)$ & $4314(5.81)$ & 2711(3.65) & $18244(24.57)$ & \\
\hline \multirow[t]{3}{*}{ Radiation } & & & & & & & & & 0.00 \\
\hline & Yes & $206(7.78)$ & $61(2.30)$ & $613(23.17)$ & $85(3.21)$ & $169(6.39)$ & $68(2.57)$ & $1444(54.57)$ & \\
\hline & No & 24643(20.17) & $7181(5.88)$ & $30256(24.67)$ & $12016(9.83)$ & $7789(6.37)$ & $5019(4.11)$ & $35286(28.88)$ & \\
\hline
\end{tabular}

* Characteristics differ by site group, Chi-square tests; all $\mathrm{P}<.0001$. AC = adenocarcinoma; Mu = mucinous adenocarcinoma; SRC = signet ring cell carcinoma; His- = histological type.
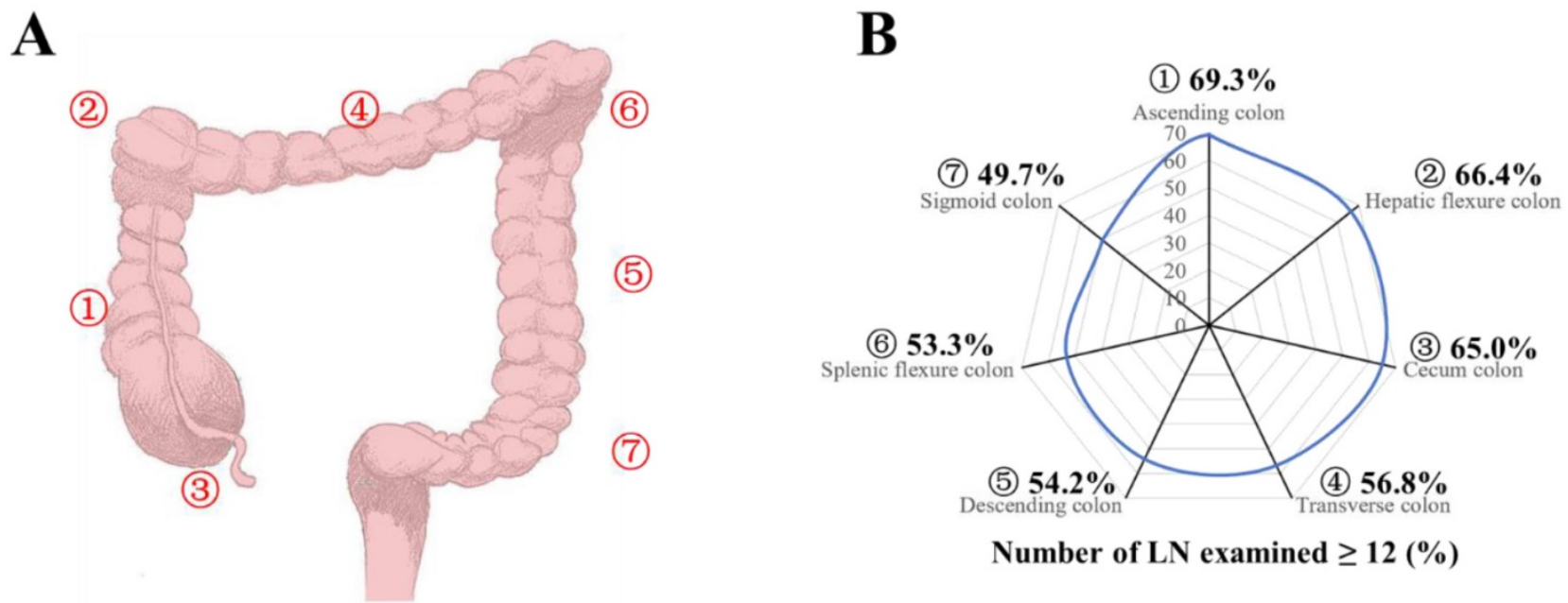

Number of LN examined $\geq 12(\%)$

Figure 1. A: Seven tumor sites of colon cancer were defined as ascending (1), hepatic (2), cecum (3), transverse (4), descending (5), splenic (6), and sigmoid colons (7). B: Proportion of patients with adequate $(\geq 12) \mathrm{LN}$ harvest in the surgical specimen from colon resection, by site group. 


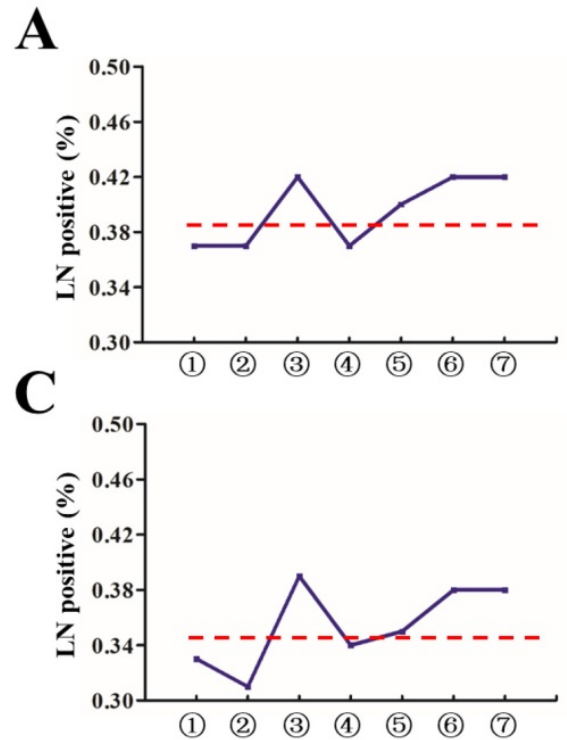

B

D
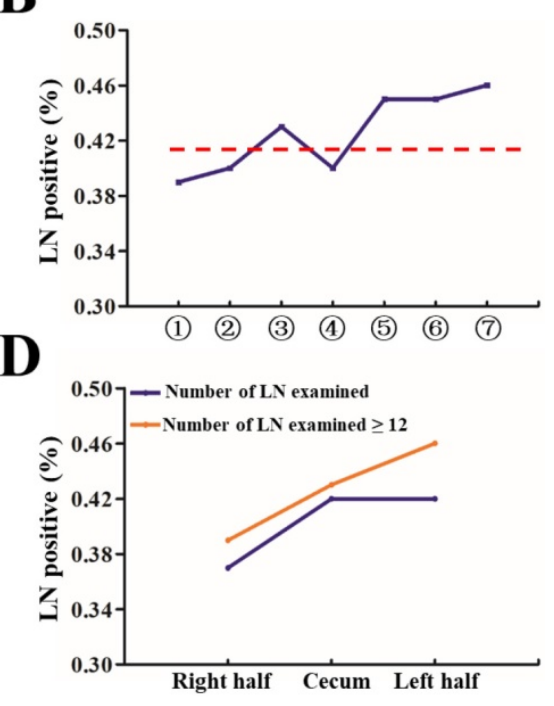

Figure 2. Proportion of patients with at least one positive LN by site and T stage. (A) All patients, divided into seven groups as described in Figure 1A; (B) Group with number of $L N$ examined < 12; (C) Group with number of number of $L N$ examined $\geq 12$; (D) All patients, divided into three groups: cecum, right and left side colon.

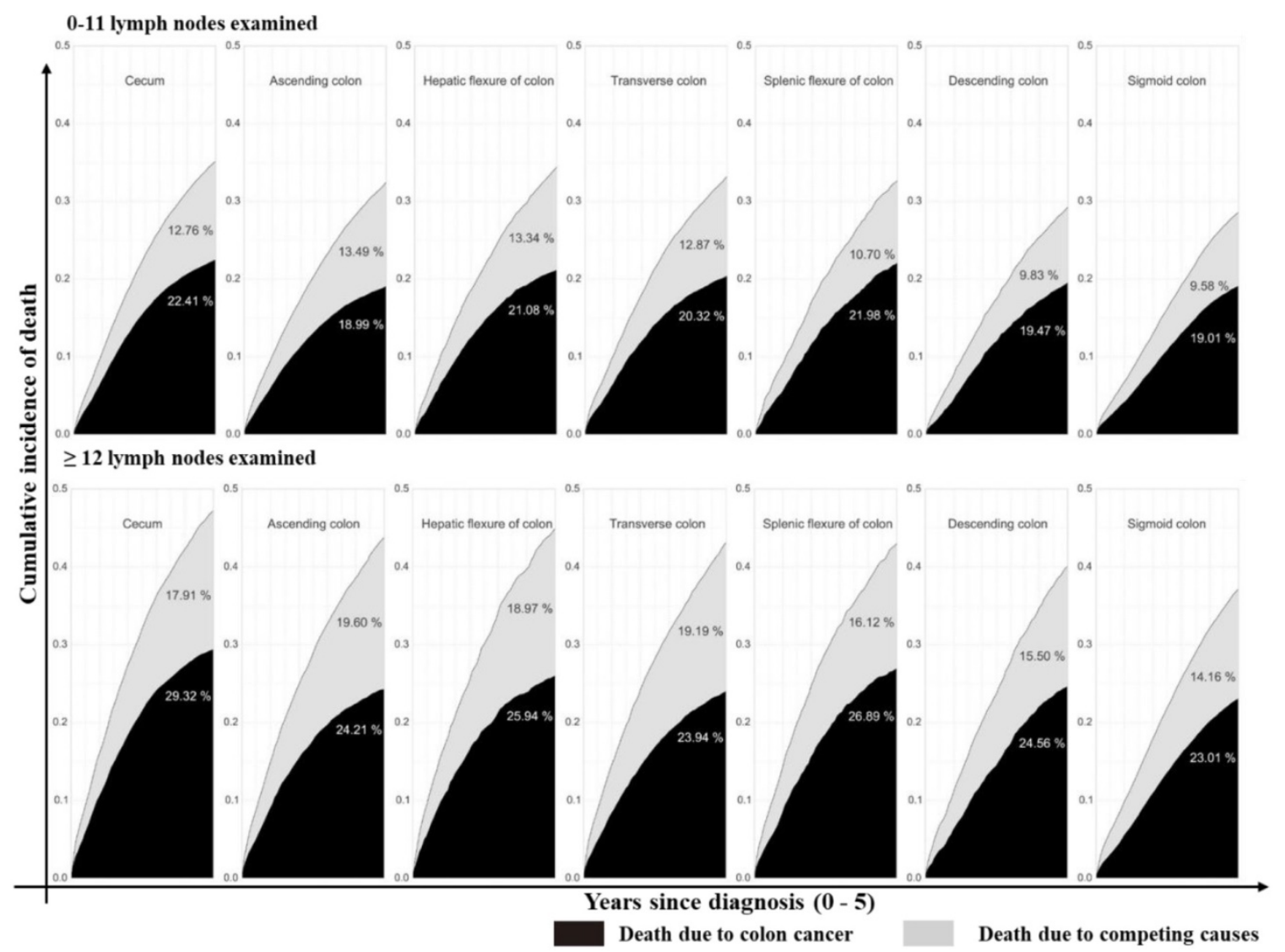

Figure 3. Stacked cumulative incidence of death due to colon cancer and competing causes in subgroups defined by sites and number of $L N s$ examined in the surgical specimen. Values for cumulative incidence of death from each type of event at 5 years are listed for each subgroup. Patients were divided into seven groups as described in Figure 1A. The upper line is patients with $0-11 \mathrm{LNs}$ examined while the bottom line is patients with $\geq 12 \mathrm{LNs}$ examined. Black area represents death due to colon cancer; gray area represents death due to competing causes.

\section{Discussion}

Multiple clinical parameters, such as $\mathrm{T}$ stage, histologic grade, the number of LNs examined, and tumor location, are thought to influence the survival in colon cancer patients[9]. However, the prognostic relevance of laterality in colon cancer, mainly 
classified by the left and right hemi-colon, has been explored with conflicting results. Here, for the first time, we divided the whole colon into seven parts to analyze the association of tumor sites with various clinical parameters and prognosis of patients who underwent early-stage colon cancer resection from a large population-based SEER database.

Several important findings have been found in our study. Firstly, after seven different tumor parts of colon cancer were classified as ascending, hepatic, cecum, transverse, descending, splenic, and sigmoid colons in terms of their anatomical sites, the number of LNs examined and adequate LNs harvest decreased gradually following the order from site 1 to 7. However, Patients with sigmoid colon cancer had the highest risk of LN positivity as well as more depth of tumor invasion. Secondly, compared with tumors at the other six sites, cecum colon cancer is associated with elder age, was a special type of colon cancer, harboring more mucinous adenocarcinoma and signet ring cell carcinoma, with more grade III/ IV and more
LN metastasis. Although more adequate LNs harvest was retrieved, cecum colon cancer patients suffered the highest cancer-related mortality among all tumors. Thirdly, CID was higher in patients with inadequate LNs harvest except for the cecum colon cancer that CID is independent of the number of LNs harvest, but there was no significant difference in the benefit between the site groups.

Table 2A. Number of LN examined by site in all stages

\begin{tabular}{llllll}
\hline Primary site & \multicolumn{2}{l}{ T stage 1-4 } & & \\
\cline { 2 - 6 } & LNE & Mean & $\mathbf{2 5}^{\text {th }}$ & $\mathbf{5 0}^{\text {th }}$ & $\mathbf{7 5}^{\text {th }}$ \\
\hline (1) Ascending colon & 426514 & 17.03 & 10 & 15 & 22 \\
(2) Hepatic flexure colon & 120668 & 16.58 & 10 & 15 & 21 \\
(3) Cecum colon & 489101 & 15.74 & 10 & 14 & 20 \\
(4) Transverse colon & 182103 & 14.96 & 8 & 13 & 19 \\
(5) Descending colon & 112626 & 14.06 & 7 & 12 & 18 \\
(6) Splenic flexure colon & 71417 & 13.98 & 7 & 12 & 18 \\
(7) Sigmoid colon & 480836 & 12.98 & 7 & 11 & 17 \\
Total & 1883265 & 14.98 & $P^{*}<0.0001$ & \\
\hline
\end{tabular}

* Qreg $=$ Trend estimated using quantile regression model, within all stages. LNE = no. lymph nodes examined.

Table 2B. Number of LN examined by site and stage (stage T1-T4)

\begin{tabular}{|c|c|c|c|c|c|c|c|c|c|c|c|c|}
\hline \multirow[t]{2}{*}{ Primary site } & \multicolumn{3}{|l|}{ T1 } & \multicolumn{3}{|l|}{ T2 } & \multicolumn{3}{|l|}{ T3 } & \multicolumn{3}{|l|}{$\mathrm{T} 4$} \\
\hline & LNE & $50^{\text {th }}$ & $25^{\text {th }}, 75^{\text {th }}$ & LNE & $50^{\text {th }}$ & $25^{\text {th }}, 75^{\text {th }}$ & LNE & $50^{\text {th }}$ & $25^{\text {th }}, 75^{\text {th }}$ & LNE & $50^{\text {th }}$ & $25^{\text {th }}, 7^{\text {th }}$ \\
\hline (1) Ascending colon & 19305 & 13 & 9,20 & 60759 & 14 & 10,20 & 230619 & 17 & 12,23 & 112414 & 14 & 9,20 \\
\hline (2) Hepatic flexure of colon & 3895 & 12 & 8,18 & 14029 & 14 & 8,19 & 23484 & 16 & 11,23 & 38324 & 13 & 9,20 \\
\hline (3) Cecum & 16157 & 13 & 8,18 & 74173 & 14 & 9,17 & 91528 & 15 & 11,21 & 159477 & 13 & 9,19 \\
\hline (4) Transverse colon & 6391 & 10 & 5,16 & 19991 & 11 & 6,17 & 32585 & 14 & 9,21 & 60411 & 12 & 7,18 \\
\hline (5) Descending colon & 3725 & 8 & 4,14 & 11603 & 11 & 6,16 & 26262 & 14 & 9,19 & 36547 & 11 & 7,17 \\
\hline (6) Splenic flexure of colon & 1705 & 10 & 4,15 & 6310 & 11 & 6,16 & 16485 & 13 & 9,19 & 25613 & 11 & 7,17 \\
\hline (7) Sigmoid colon & 23609 & 8 & 5,14 & 68248 & 10 & 6,16 & 92270 & 13 & 8,18 & 147727 & 10 & 6,16 \\
\hline $\mathbf{P}^{*}$ & & & $>0.01$ & & & $<0.0001$ & & & $<0.0001$ & & & $<0.0001$ \\
\hline
\end{tabular}

${ }^{*}$ Qreg $=$ Trend estimated using quantile regression model, within each stage. LNE $=$ no. lymph nodes examined.

A

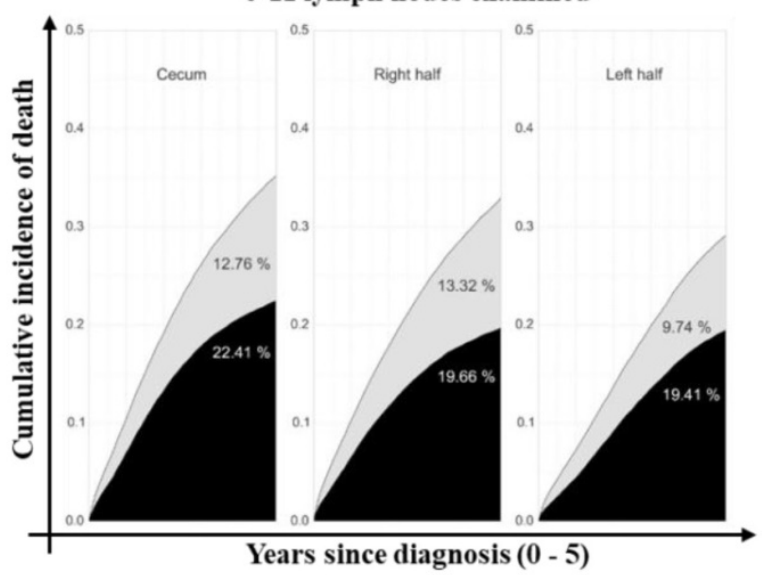

B

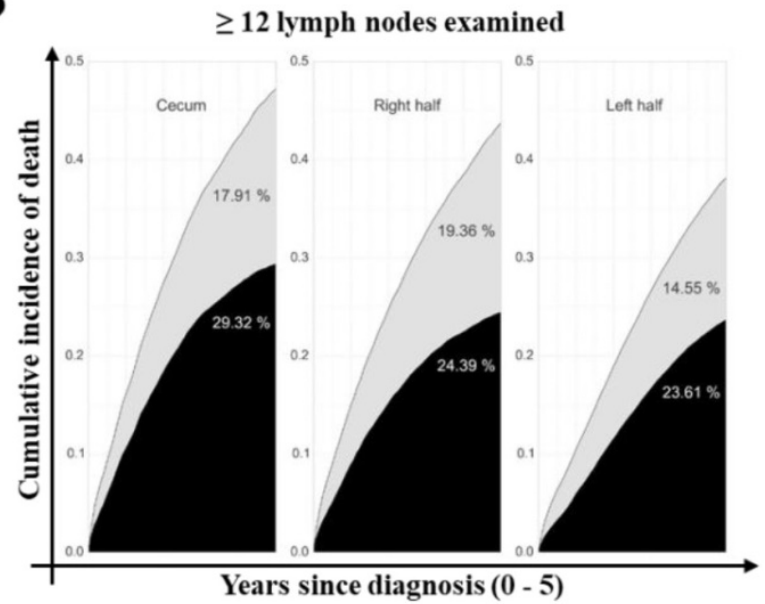

Figure 4. Stacked cumulative incidence of death due to colon cancer and competing causes in subgroups defined by site and number of LNs examined in the surgical specimen. Values for cumulative incidence of death from each type of event at 5 years are listed for each subgroup. All patients were divided into three groups: cecum, right and left side colon. Black area represents death due to colon cancer; gray area represents death due to competing causes. 
Table 3. Association of site and adequate LN harvest $(\geq 12)$

\begin{tabular}{|c|c|c|c|c|}
\hline \multirow[t]{2}{*}{ Primary site } & \multicolumn{2}{|c|}{ Multivariate analysis } & \multicolumn{2}{|c|}{$\begin{array}{l}\text { Adjusting-Multivariate } \\
\text { analysis }\end{array}$} \\
\hline & RR(95\%CI) & $\mathbf{P}^{*}$ & RR(95\%CI) & $\mathbf{P}^{*}$ \\
\hline (1) Ascending colon & $\begin{array}{l}1.396 \\
(1.378-1.415)\end{array}$ & 0.000 & $\begin{array}{l}1.355 \\
(1.337-1.373)\end{array}$ & 0.000 \\
\hline $\begin{array}{l}\text { (2) Hepatic flexure } \\
\text { colon }\end{array}$ & $\begin{array}{l}1.336 \\
(1.310-1.362)\end{array}$ & 0.000 & $\begin{array}{l}1.301 \\
(1.277-1.326)\end{array}$ & 0.000 \\
\hline (3) Cecum colon & $\begin{array}{l}1.309 \\
(1.292-1.326)\end{array}$ & 0.000 & $\begin{array}{l}1.285 \\
(1.269-1.302)\end{array}$ & 0.000 \\
\hline (4) Transverse colon & $\begin{array}{l}1.144 \\
(1.123-1.165)\end{array}$ & 0.000 & $\begin{array}{l}1.129 \\
(1.109-1.150)\end{array}$ & 0.000 \\
\hline (5) Descending colon & $\begin{array}{l}1.091 \\
(1.067-1.116)\end{array}$ & 0.000 & $\begin{array}{l}1.079 \\
(1.055-1.104)\end{array}$ & 0.000 \\
\hline $\begin{array}{l}\text { (6) Splenic flexure } \\
\text { colon }\end{array}$ & $\begin{array}{l}1.073 \\
(1.044-1.103)\end{array}$ & 0.000 & $\begin{array}{l}1.058 \\
(1.030-1.087)\end{array}$ & 0.000 \\
\hline (7) Sigmoid colon & Ref. & Ref. & Ref. & Ref. \\
\hline
\end{tabular}

*P values for site group variable in each logistic regression model. The adjusted model included year of diagnosis, sex, race, age, grade, histological type, T stage, and adjunctive therapy. All statistical tests were two-sided. $\mathrm{CI}=$ confidence interval; Ref. $=$ referent; $R R=$ relative risk.

Table 4. Association of site and number of positive LNs in patients with adequate $L N$ harvest $(\geq 12)$

\begin{tabular}{|c|c|c|c|c|c|}
\hline \multirow[t]{2}{*}{ Parameter } & \multirow[t]{2}{*}{ Characteristic } & \multicolumn{2}{|c|}{ Multivariate analysis } & \multicolumn{2}{|c|}{$\begin{array}{l}\text { Adjusting } \\
\text {-Multivariate analysis }\end{array}$} \\
\hline & & RR(95\%CI) & $\mathrm{P}^{*}$ & RR(95\%CI) & $\mathrm{P}^{*}$ \\
\hline \multicolumn{6}{|c|}{ Primary site 1} \\
\hline & $\begin{array}{l}\text { (1)Ascending } \\
\text { colon }\end{array}$ & $\begin{array}{l}0.856 \\
(0.835-0.877)\end{array}$ & 0.000 & $\begin{array}{l}0.856 \\
(0.836-0.877)\end{array}$ & 0.000 \\
\hline & $\begin{array}{l}\text { (2)Hepatic } \\
\text { flexure colon }\end{array}$ & $\begin{array}{l}0.867 \\
(0.835-0.901)\end{array}$ & 0.000 & $\begin{array}{l}0.858 \\
(0.827-0.891)\end{array}$ & 0.000 \\
\hline & $\begin{array}{l}\text { (3)Cecum } \\
\text { colon }\end{array}$ & $\begin{array}{l}0.936 \\
(0.915-0.957)\end{array}$ & 0.000 & $\begin{array}{l}0.933 \\
(0.913-0.954)\end{array}$ & 0.000 \\
\hline & $\begin{array}{l}\text { (4)Transverse } \\
\text { colon }\end{array}$ & $\begin{array}{l}0.867 \\
(0.839-0.897)\end{array}$ & 0.000 & $\begin{array}{l}0.854 \\
(0.827-0.882)\end{array}$ & 0.000 \\
\hline & $\begin{array}{l}\text { (5)Descending } \\
\text { colon }\end{array}$ & $\begin{array}{l}0.976 \\
(0.941-1.013)\end{array}$ & 0.021 & $\begin{array}{l}0.954 \\
(0.922-0.988)\end{array}$ & 0.000 \\
\hline & $\begin{array}{l}\text { (6)Splenic } \\
\text { flexure colon }\end{array}$ & $\begin{array}{l}1.003 \\
(0.959-1.048)\end{array}$ & 0.635 & $\begin{array}{l}0.956 \\
(0.917-0.997)\end{array}$ & 0.000 \\
\hline & $\begin{array}{l}\text { (7)Sigmoid } \\
\text { colon }\end{array}$ & Ref. & Ref. & Ref. & Ref. \\
\hline \multicolumn{6}{|c|}{ Primary site 2} \\
\hline & $\begin{array}{l}\text { (1)Right } \\
\text { hemi-colon }\end{array}$ & $\begin{array}{l}0.865 \\
(0.848-0.882)\end{array}$ & 0.000 & $\begin{array}{l}0.868 \\
(0.851-0.885)\end{array}$ & 0.000 \\
\hline & (2)Cecum & $\begin{array}{l}0.939 \\
(0.920-0.959)\end{array}$ & 0.000 & $\begin{array}{l}0.946 \\
(0.927-0.966)\end{array}$ & 0.000 \\
\hline & $\begin{array}{l}\text { (3)Left } \\
\text { hemi-colon }\end{array}$ & Ref. & Ref. & Ref. & Ref. \\
\hline
\end{tabular}

*P values for site group variable in each logistic regression model. The adjusted model included year of diagnosis, sex, race, age, grade, histological type, T stage, and adjunctive therapy. All statistical tests were two-sided. CI = confidence interval; Ref. $=$ referent; $\mathrm{RR}=$ relative risk .

The extent to which the location (classified by left and right hemi-colon) of colon cancer affects the prognosis is still controversial. So far, there have been three mainly different opinions[5, 12-14]. Karim et al.[5] and Weiss et al.[19] held the opinion that disease laterality was not associated with survival across all stages although in the subgroup analysis, Karim et al. demonstrated a trend toward an improved outcome among patients with right-sided stage II disease while Weiss et al. found greater overall mortality with right-sided disease in stage III [5, 19]. Lim et al.[12], Yahagi et al.[13] and others[14], found lower survival in patients with right-sided cancer than that of left-sided. Lim et al.[12] found that left-sided cancer had better survival outcomes than right-sided one after curative resection, especially in stage III. While Warschkow et al.[20] reported that after propensity score matching, right-sided colon carcinomas had better prognosis.

In this study, we found that LNs dissection was closely related to the prognosis of colon cancer patients. CID was higher in patients with less LN examined except for the group of cecum colon cancer, but there was no significant difference between all groups. We also showed that among all seven tumor sites, cecum colon cancer had its unique biological characteristics as it is most likely to appear in elderly patients, has more mucinous adenocarcinoma and signet ring cell carcinoma, with more grade III/IV, and more LN metastasis. Most researchers considered cecum to be as a part of right hemi-colon according to embryological homology[5, 12-14, 20]. During the development, the right-sided colon (cecum, ascending colon, and proximal two-thirds of the transverse colon) raised from the midgut, while the left-sided colon (distal one-third of the transverse colon, descending colon, and sigmoid colon) raised from the hindgut[21-22]. However, we found that cecum colon cancer patients suffered highest cancer-related mortality among all other-site tumors. As regards of treatment, it might not be reasonable to classify the cecum into the right hemi-colon. Furthermore, our results also suggested that right hemi-colon (ascending, hepatic and transverse) be a significant predictor of an increased number of LNs examined and adequate LNs harvest at diagnosis, but with decreased risk of LN positivity. This may be due to the distribution of LNs which was mainly along the artery [23]. Moreover, the high positive rate of LNs in the left hemi-colon might be related to less number of LNs dissected.

The results of this study had several potential limitations. First, the SEER database did not include information of therapeutic options such as detailed data of chemotherapy, recurrence and metastasis, which might impact patients' prognosis[24]. Second, different operative doctors and pathologist would affect the detective rate of total LNs and metastatic LNs, but the SEER did not include these information [25]. Third, the competing risk methodology allowed the separation of cancer-related deaths and events related to other medical problems[16]. This analysis relied on the assumption of identical background mortality in colon cancer patients as in the general population, which could not be verified[16].

In conclusion, our study showed that right hemi-colon at diagnosis is a significant predictor of an 
increased number of LN examined and adequate LN harvest, but with decreased risk of LN positivity. Cecum colon cancer was more likely to be a special type of colon cancer with a worse survival. Since the survival benefits of the site groups were similar except for cecum colon cancer, current guidelines for extent of resection may require reconsideration and unnecessary treatment might be avoided. Further study is needed to identify which site-subsets of patients derive the most potential benefit from current management recommendations.

\section{Supplementary Material}

Supplementary tables.

http://www.jcancer.org/v10p2376s1.pdf

\section{Acknowledgements}

This work was supported by grants from National Natural Science Foundation of China (81402002). The authors acknowledged the efforts of the Surveillance, Epidemiology, and End Results (SEER) Program tumor registries in the creation of the SEER database. The interpretation and reporting of these data were the sole responsibility of the authors.

\section{Author Contributions}

XXL planned the study. HLW and XWL calculated statistics and analyzed the data. YYX, RQ and $\mathrm{YH}$ wrote the manuscript. $\mathrm{ZQH}$ and $\mathrm{XXL}$ supervised the entire project. All authors reviewed the manuscript.

\section{Competing Interests}

The authors have declared that no competing interest exists.

\section{References}

1. Ferlay J, Soerjomataram I, Dikshit R, Eser S, Mathers C, Rebelo M, et al. Cancer incidence and mortality worldwide: sources, methods and major patterns in GLOBOCAN 2012. International journal of cancer. 2015;136:E359-86.

2. Chen $W$, Zheng R, Baade PD, Zhang S, Zeng H, Bray F, et al. Cancer statistics in China, 2015. CA: a cancer journal for clinicians. 2016;66:115-32.

3. West NP, Quirke P. Colon cancer surgery: pathological quality control is essential for optimal outcomes. Colorectal disease : the official journal of the Association of Coloproctology of Great Britain and Ireland. 2018;20 Suppl 1:34-5.

4. Delattre O, Olschwang S, Law DJ, Melot T, Remvikos Y, Salmon RJ, et al. Multiple genetic alterations in distal and proximal colorectal cancer. Lancet. 1989;2:353-6.

5. Karim S, Brennan K, Nanji S, Berry SR, Booth CM. Association Between Prognosis and Tumor Laterality in Early-Stage Colon Cancer. JAMA oncology. 2017;3:1386-92.

6. Peyravian N, Larki P, Gharib E, Nazemalhosseini-Mojarad E, Anaraki F, Young C, et al. The Application of Gene Expression Profiling in Predictions of Occult Lymph Node Metastasis in Colorectal Cancer Patients. Biomedicines. $2018 ; 6$.

7. Zong L, Abe M, Ji J, Zhu WG, Yu D. Tracking the Correlation Between CpG Island Methylator Phenotype and Other Molecular Features and Clinicopathological Features in Human Colorectal Cancers: A Systematic Review and Meta-Analysis. Clinical and translational gastroenterology. 2016:7:e151.

8. Bae JM, Kim MJ, Kim JH, Koh JM, Cho NY, Kim TY, et al. Differential clinicopathological features in microsatellite instability-positive colorectal cancers depending on CIMP status. Virchows Archiv : an international journal of pathology. 2011;459:55-63.
9. Bettington $\mathrm{M}$, Walker $\mathrm{N}$, Clouston A, Brown I, Leggett B, Whitehall V. The serrated pathway to colorectal carcinoma: current concepts and challenges. Histopathology. 2013;62:367-86.

10. ZR, Liao X, et al. Analyses of clinicopathological, molecular, and prognostic associations of KRAS codon 61 and codon 146 mutations in colorectal cancer: cohort study and literature review. Molecular cancer. 2014;13:135.

11. Lee S, Cho NY, Choi M, Yoo EJ, Kim JH, Kang GH. Clinicopathological features of $\mathrm{CpG}$ island methylator phenotype-positive colorectal cancer and its adverse prognosis in relation to KRAS/BRAF mutation. Pathology international. 2008;58:104-13.

12. Lim DR, Kuk JK, Kim T, Shin EJ. Comparison of oncological outcomes of right-sided colon cancer versus left-sided colon cancer after curative resection: Which side is better outcome? Medicine. 2017;96:e8241.

13. Yahagi M, Okabayashi $K$, Hasegawa $H$, Tsuruta M, Kitagawa $Y$. The Worse Prognosis of Right-Sided Compared with Left-Sided Colon Cancers: a Systematic Review and Meta-analysis. Journal of gastrointestinal surgery : official journal of the Society for Surgery of the Alimentary Tract. 2016;20:648-55

14. Tejpar S, Stintzing S, Ciardiello F, Tabernero J, Van Cutsem E, Beier F, et al. Prognostic and Predictive Relevance of Primary Tumor Location in Patients With RAS Wild-Type Metastatic Colorectal Cancer: Retrospective Analyses of the CRYSTAL and FIRE-3 Trials. JAMA oncology. 2016.

15. Ho JW, Stefani M, dos Remedios CG, Charleston MA. A model selection approach to discover age-dependent gene expression patterns using quantile regression models. BMC genomics. 2009;10 Suppl 3:S16

16. Khan H, Olszewski AJ, Somasundar P. Lymph node involvement in colon cancer patients decreases with age; a population based analysis. European journal of surgical oncology : the journal of the European Society of Surgical Oncology and the British Association of Surgical Oncology. 2014;40:1474-80.

17. Perme MP, Stare J, Esteve J. On estimation in relative survival. Biometrics. 2012;68:113-20.

18. Cronin KA, Feuer EJ. Cumulative cause-specific mortality for cancer patients in the presence of other causes: a crude analogue of relative survival. Statistics in medicine. 2000;19:1729-40.

19. Weiss JM, Pfau PR, O'Connor ES, King J, LoConte N, Kennedy G, et al. Mortality by stage for right- versus left-sided colon cancer: analysis of surveillance, epidemiology, and end results--Medicare data. Journal of clinical oncology : official journal of the American Society of Clinical Oncology. 2011;29:4401-9

20. Warschkow R, Sulz MC, Marti L, Tarantino I, Schmied BM, Cerny T, et al. Better survival in right-sided versus left-sided stage I - III colon cancer patients. BMC cancer. 2016;16:554.

21. Glebov OK, Rodriguez LM, Nakahara K, Jenkins J, Cliatt J, Humbyrd CJ, et al. Distinguishing right from left colon by the pattern of gene expression. Cancer pidemiology, biomarkers \& prevention : a publication of the American Association for Cancer Research, cosponsored by the American Society of Preventive Oncology. 2003;12:755-62.

22. Somatic profiling of the epidermal growth factor receptor pathway in tumors from patients with advanced colorectal cancer treated with chemotherapy

23. Higashijima J, Shimada M, Iwata T, Yoshikawa K, Nakao T, Nishi M, et al. New ports placement in laparoscopic central lymph nodes dissection with left colic artery preservation for sigmoid colon and rectal cancer. The journal of medical investigation: JMI. 2015;62:223-7.

24. Li X, Zhang W, Zhang X, Wang H, Xu K, Yao H, et al. The prognostic value of negative lymph node count for patients with gastric cancer who received preoperative radiotherapy. Oncotarget. 2017;8:46946-54

25. Lu H, Guo R, Yang H, Wang H, Liang X, Hu Z, et al. The prognostic value of negative lymph node count for patients with cervical cancer after radical surgery. Oncotarget. 2018;9:2810-8. 